\title{
Problem-based Learning and Team-based Learning as a Novel Package Approach
}

\author{
Shazia Nawabi ${ }^{1}$, Muhammad Qasim Javed ${ }^{2}$ and Rabia Bilal ${ }^{3}$ \\ ${ }^{1}$ Department of Prosthodontics and Chair Dental Education Unit, College of Dentistry, Qassim University, Saudi Arabia \\ ${ }^{2}$ Department of Conservative Dental Sciences and Endodontics, College of Dentistry Qassim University, Saudi Arabia. \\ ${ }^{3}$ Departments of Orthodontics, College of Dentistry, Qassim University, Saudi Arabia
}

\begin{abstract}
Objective: To identify the insights of dentistry students towards a new 3/1 problem-based learning (PBL) and team-based learning (TBL) blended package approach.

Study Design: Mixed method triangulation design, using validating quantitative data model.

Place and Duration of Study: College of Dentistry, Qassim University, KSA, from March to July 2020.

Methodology: Modified TBL within an existing PBL hybrid curriculum, by strategically designing three modified PBL sessions followed by one modified TBL session was evaluated. There were 241 students enrolled over five academic years of session 2019-2020, and all were included in the study. Feedback of the students regarding novel approach was collected at the culmination of the academic year through an e-questionnaire, utilising closed- and open-ended questions. Descriptive statistics and thematic analysis were used to analyse data.

Results: In total, 124 (51.5\%) students filled a questionnaire regarding use of PBL and TBL in the new blended approach. The median perception score of TBL was 3.9 (3.2-4.3) and PBL was 3.9 (3.3-4.3). Thematic analysis of the qualitative data supported the quantitative results. Students reported positive aspects of TBL experience as more engaging format, collaborative learning, teamwork, and group competition. They stated that PBL has improved their research, presentation, and clinical reasoning skills.

Conclusion: Students valued the novel PBL-TBL package as an optimum learning approach. They predominantly voted in favour of TBL. Students further identified the sequence and format of the current approach conducive to learning, feedback and assessment.
\end{abstract}

Key Words: Hybrid curriculum, Team-based learning, Problem-based learning, Blended learning, Innovative instructional strategy.

How to cite this article: Nawabi S, Javed MQ, Bilal R. Problem-based Learning and Team-based Learning as a Novel Package Approach. J Coll Physicians Surg Pak 2021; 31(06):710-715.

\section{INTRODUCTION}

Active learning has become a buzzword for medical educators since the advent of problem-based learning (PBL), almost half a century ago to the more recently evolved team-based learning (TBL). ${ }^{1}$ The co-existence of PBL and TBL in medical education confirms the fact that both fit well within current instructional design principles. ${ }^{2}$ Therefore, medical schools all over the world have been compelled to recognise and adopt these major breakthroughs in curriculum reform.

PBL is one of the most substantial innovations in the history of education, ${ }^{3}$ pioneered by Barrows and Tamblyn at the McMaster University's medical school programme in Hamilton in the 1960s. ${ }^{4}$

Correspondence to: Dr. Shazia Nawabi, Department of Prosthodontics and Chair Dental Education Unit, College of Dentistry, Qassim University, Saudi Arabia

E-mail:dr.shazia.nawabi@qudent.org

Received: September 05, 2020; Revised: December 09, 2020;

Accepted: February 24, 2021

DOI: https://doi.org/10.29271/jcpsp.2021.06.710
It augments student-centered approach, upholds lifelong self-directed learning, confirms constructive approach and compliments integrated learning by identifying curriculum core. 5,6 $\mathrm{TBL}$, on the other hand, is a highly structured collaborative learning strategy that retains the educational powers of $\mathrm{PBL}$ in a more resource-friendly way. TBL was devised by Larry Michaelson, at the University of Oklahoma Business School in the late 1970s. ' Later, the concept was popularised and came to the attention of medical education in the late 1990s when Boyd Richards and colleagues began piloting it at Baylor School of Medicine. It inculcates individual accountability, high-level studentengagement and group cohesiveness. ${ }^{8}$

Medical educators have been inspired to adopt innovative instructional strategies. Medical schools all over the world regularly modify their curricula to prepare their graduates for the changing world of the health professions. ${ }^{2}$ Regardless of the flag under which the curriculum sails, important is to discover variety of approaches which, when blended, lead to authentic learning by achieving particular curricular outcomes. ${ }^{9}$

This study reported a five-year experience of implementing a blended PBL and TBL. The authors tried to meticulously 
combine the best of both worlds to maximise their joint educational powers, and named it a package approach.

The objective of present study was to explore the insights of students regarding PBL and TBL as a novel package approach. Since the team of researchers is the member of dental education unit, consequently the results of this study might be used to modify the design of blended approach depending upon which learning strategy is perceived more positive.

\section{METHODOLOGY}

The study was conducted at College of Dentistry, Qassim University from March to July 2020. Ethical approval (ST/6070/2020) was obtained from the Institutional Ethical Review Committee. This cross-sectional study used mixed method triangulation design using validating quantitative data model where quantitative and qualitative data were collected simultaneously. Non-probability convenience sampling technique was used to include undergraduate dental students as study participants. Before commencing the study, all the students were informed about the background and purpose of the research. Subsequently, an online e-questionnaire was sent through an electronic mail to 241 dental students, at the end of the academic year. All the students who filled e-forms were included; and who did not fill, were excluded from the study.

Qassim College of Dentistry is implementing a hybrid PBL curriculum (H-PBL), for the past 10 years. The curriculum is recognised by the Saudi Commission for Health Specialities, accredited by the National Commission for Academic Accreditation and Assessment, and supported by a growing body of literature in the field of dental education. ${ }^{10}$ Seventy percent of the curricular component was traditional lectures reinforced by $30 \% \mathrm{PBL}$, until this approach (H-PBL) was further modified five years back, with the inclusion of $10 \%$ TBL as 3/1 PBL-TBL package, making conventional and interactive teaching modalities more balanced. Orientation of faculty and students with TBL process is done by a set of workshops by Dental Education Unit at the start of each academic year. There are three PBLs, followed by one TBL session for each theme of the block, at all academic levels, from first to fourth year. We have separate male and female campuses with the maximum number of 25 students in each class. Our student teams consist of 6 to 8 students for TBLand 8 to 10 students for PBL.

Each PBL is traditionally conducted in two tutors-led sessions per week. In between sessions, students work on their objectives individually as well as in groups, using an online discussion board under supervision of respective tutors. The discussion board is also used to provide peer and tutor feedback. During the second PBL session, students present their objectives in the form of PowerPoint presentations, and tutors assess them formatively against a criterion-referenced checklist. The concept to develop English communication skills through PBL strategy is contextual; as in Saudi Arabia, most of the high school teaching is provided in Arabic. Therefore, the shift to an
English-based learning environment may be difficult for some students. ${ }^{11}$

The TBL follows an established sequence of activities as recommended by the AMEE guide No. $65,{ }^{12}$ with slight modification. In addition to reference sent to students according to theme of the week, the authors also use TBL to assess learning objectives derived in the last three PBL sessions. TBL process consists of 20 minutes MCQ-based, individual readiness assurance e-test (IRAT) at the start of session, followed by same test in groups as group readiness assurance test (G-RAT) for further 20 minutes. Results are displayed promptly after completion of both tests and immediate feedback or clarification of any concept is given by the content expert. Subsequently, it is followed by 60 minutes application exercise.

The whole conduction and assessment system of PBL and TBL is electronic. The online assessment form with standardised rubric criterion for content and context is submitted by relevant tutors on completion of both sessions. There are 60 points for each PBL, 30 for both sessions ( 15 each) and 30 for discussion board (structured feedback). Total weightage of all the PBLs in each block is 10 points. There are 5 points for TBL in one block. All TBL sessions are facilitated by trained dental education unit members.

The validated questionnaire, developed by Burgess and colleagues, ${ }^{13}$ was utilised in the study with permission. The five-point Likert scale was used for 12 closed ended questions, where five was "strongly agree" and one was "strongly disagree". Five open-ended questions were also used to ascertain their views about useful and difficult features of both active learning strategies to package approach.

Data was analysed using SPSS version 23 (IBM Corp, 32 Armonk, N.Y., USA). Descriptive statistics were recorded as median (IQR) along with percentages and frequencies. The association between the categorical variables was determined by using Chi-square test. The level of significance was set at below 0.05 ( $p$-value< 0.05 ). Thereafter, for evaluating the significance among study variables, inferential statistics were used (Kruskal-Wallistest and Mann-Whitney U-test).

Validation of quantitative data through cross verification was planned to provide clearer understanding of the problem and to increaseconfidence intheresults. Categorisation of the qualitative data into themes was carried out by conducting the content thematic analysis using inductive coding. Quantification of data set within different themes was done for measuring the thematic prevalence.

\section{RESULTS}

Out of 241 students, 124 (51.5\%) responded to the survey questionnaires. The lowest response rate 20 out of 49 (40.8\%) was noted for the final year students; and highest 20 out of $36(55.6 \%)$ for the first-year students. The female to male ratio of the respondents was 1.14:1. The median perception score of the students for PBL was slightly higher than TBL. (Table I). 
Table I: Students' perception about problem-based learning and team-based learning.

\begin{tabular}{|c|c|c|c|c|c|c|}
\hline \multirow{3}{*}{ Items } & \multicolumn{2}{|c|}{$\begin{array}{l}\text { Median (IQR) perception } \\
\text { score }\end{array}$} & \multicolumn{4}{|c|}{ p-value } \\
\hline & \multirow[b]{2}{*}{ PBL } & \multirow[b]{2}{*}{ TBL } & \multicolumn{2}{|c|}{ PBL } & \multicolumn{2}{|c|}{ TBL } \\
\hline & & & Gender $^{2}$ & $\begin{array}{l}\text { Academic } \\
\text { Year }^{3}\end{array}$ & Gender $^{2}$ & $\begin{array}{l}\text { Academic } \\
\text { Year }^{3}\end{array}$ \\
\hline $\begin{array}{l}\text { 1-All team members made an effort to participate in the } \\
\text { discussion }\end{array}$ & $4(3.25-5.0)$ & $4(3.0-5.0)$ & 0.52 & 0.41 & $* 0.03$ & 0.69 \\
\hline $\begin{array}{l}\text { 2-Team members encouraged one another to express their } \\
\text { opinions }\end{array}$ & $4(3.0-5.0)$ & $4(3.0-5.0)$ & 0.41 & 0.48 & 0.88 & 0.82 \\
\hline 3-Different points of view were respected by team members & $4(4.0-5.0)$ & $4(4.0-5.0)$ & 0.68 & 0.74 & 0.72 & 0.78 \\
\hline $\begin{array}{l}\text { 4-Team actively elicited multiple points of view before } \\
\text { deciding on final answer }\end{array}$ & $4(3.0-5.0)$ & $4(3.25-5.0)$ & 0.37 & 0.80 & 0.11 & 0.61 \\
\hline $\begin{array}{l}\text { 5-All team members consistently paid attention while } \\
\text { conducting group discussions }\end{array}$ & $4(3.0-5.0)$ & $4(3.0-5.0)$ & 0.25 & 0.59 & 0.36 & 0.99 \\
\hline $\begin{array}{l}\text { 6-Team members used feedback about individual or team } \\
\text { performance to help the team to be more effective }\end{array}$ & $4(3.0-4.0)$ & $4(3.0-4.0)$ & 0.58 & 0.36 & 0.33 & 0.33 \\
\hline 7-Students did read the readings prior to sessions & $4(3.0-4.0)$ & $4(3.0-4.0)$ & 0.18 & 0.63 & 0.46 & 0.81 \\
\hline $\begin{array}{l}\text { 8-Completion of prescribed out of class preparation helped in } \\
\text { my learning }\end{array}$ & $4(3.0-4.0)$ & $4(3.0-4.0)$ & 0.16 & 0.23 & $* 0.04$ & 0.44 \\
\hline $\begin{array}{l}\text { 9-The number of group members enhanced my experience of } \\
\text { group learning }\end{array}$ & $4(3.0-4.75)$ & $4(3.0-5.0)$ & 0.66 & 0.08 & 0.08 & 0.35 \\
\hline 10-I received the useful and timely feedback from the tutor & $4(3.0-5.0)$ & $4(3.0-4.0)$ & 0.31 & 0.46 & 0.33 & 0.22 \\
\hline 11-The tutor helped to focus discussion and learning & $4(3.0-5.0)$ & $4(3.0-4.75)$ & 0.85 & 0.59 & 0.22 & 0.42 \\
\hline $\begin{array}{l}\text { 12-Problem solving allowed me to develop my clinical } \\
\text { reasoning skills }\end{array}$ & $4(3.0-4.0)$ & $4(3.0-4.0)$ & 0.57 & $* 0.001$ & 0.57 & $*<0.001$ \\
\hline
\end{tabular}

Table II: Gender and academic year-wise perception score of PBL and TBL.

\begin{tabular}{|c|c|c|c|c|c|c|c|}
\hline Description & $\mathbf{N}(\%)$ & Median PBL score (IQR) & Mean Rank & p-value & Median TBL Score (IQR) & Mean Rank & p-value \\
\hline \multicolumn{8}{|l|}{ Gender** } \\
\hline Male & $58(46.8)$ & $3.87(3.08-4.18)$ & 58.03 & \multirow{2}{*}{0.19} & $3.71(3.00-4.11)$ & 53.62 & \multirow{2}{*}{0.01} \\
\hline Female & $66(53.2)$ & $4.00(3.46-4.50)$ & 66.42 & & $4.00(3.36-4.38)$ & 70.30 & \\
\hline \multicolumn{8}{|l|}{ Academic Year ${ }^{*}$} \\
\hline First Year & $20(16.1)$ & $4.00(3.10-4.48)$ & 67.18 & \multirow{5}{*}{0.46} & $3.93(3.09-4.45)$ & 62.93 & \multirow{5}{*}{0.50} \\
\hline Second Year & $33(26.6)$ & $3.91(3.29-4.12)$ & 61.74 & & $4.00(3.25-4.14)$ & 63.73 & \\
\hline Third Year & $26(21.0)$ & $3.58(2.90-4.27)$ & 54.73 & & $3.46(2.98-4.25)$ & 52.19 & \\
\hline Fourth Year & $25(20.2)$ & $4.00(3.38-4.62)$ & 71.78 & & $3.93(3.25-4.50)$ & 70.18 & \\
\hline Fifth Year & $20(16.1)$ & $3.83(3.25-4.06)$ & 57.58 & & $3.86(3.52-4.23)$ & 63.85 & \\
\hline
\end{tabular}

The highest perception score for both PBL and TBL was noted for the item "Different point of views were respected by the team members"; whereas, the lowest perception score was noted for the item "Team members used feedback about individual or team performance to help the team to be more effective"' (Table I).

The gender-based item-wise analysis of the PBL questionnaire was found to be insignificant, conversely, for $T B L$, items stating "All team members made an effort to participate in the discussion" and "Completion of prescribed out of class preparation helped in my learning", showed statistically significant differences (p-value<0.05) (Table I). Furthermore, the comparison of the PBL and TBL perception scores of male and female students suggested higher female scores, with the TBL score being significantly higher ( $p<0.05$, Table II). The itembased year-wise analysis highlighted the significant difference in the perception of item "Problem solving allowed me to develop my clinical reasoning skills "for both PBL and TBL ( $p$ value $<0.05$, Table I). Moreover, fourth-year was found to have the highest perception scores, whereas third year scored lowest for both strategies.

Qualitative data were segregated to gender and question-wise to start with thematic analysis. Initial open coding was done followed by development of hierarchical coding frame regarding perceived useful and difficult features of $\mathrm{PBL}$ and TBL package approach. Themes were generated by making axial coding connections, and mapping to the conceptual framework. Emergent prevalent themes along with selective responses to open-ended questions are illustrated (Table III).

\section{DISCUSSION}

Generally, learning experience of students regarding the innovative approach was positive for both TBL and PBL. These results are in line with many studies which have compared the efficacy of team-based and problem based learning in blended modules and reported that students favoured both strategies over other learning methods. ${ }^{14,15}$ 
Table III: Students' views regarding best and challenging features of PBL and TBL.

\begin{tabular}{|c|c|c|}
\hline Emergent theme PBL & Model student's comments & Similar responses \\
\hline \multicolumn{3}{|c|}{ Best features of PBL in perspective of package approach } \\
\hline Research skills & $\begin{array}{l}\text { I like discovering new information, because when you search about the information by } \\
\text { yourself it's hard to forget. } \\
\text { It has helped me in how to find the most trusted resources and also the skill to search for } \\
\text { information from the correct and scientific sources }\end{array}$ & $37 / 124$ \\
\hline Presentation skills & $\begin{array}{l}\text { Makes me a good presenter by facing the audience and being able to talk in public. } \\
\text { It helps in self-development by increasing our confidence when we learn skill of giving } \\
\text { presentations }\end{array}$ & $33 / 124$ \\
\hline $\begin{array}{l}\text { Self-directed learning } \\
\text { skills }\end{array}$ & $\begin{array}{l}\text { It taught me depending on myself for learning and gain opportunity to collect information } \\
\text { individually } \\
\text { Self-dependence to solve a problem increases our horizons to the highest potential }\end{array}$ & 24/124 \\
\hline $\begin{array}{l}\text { Clinical reasoning } \\
\text { skills }\end{array}$ & $\begin{array}{l}\text { Teaches us how to analyse and solve the clinical problem by critical thinking in many } \\
\text { directions. } \\
\text { Group working improves our critical thinking in solving the problem. }\end{array}$ & $19 / 124$ \\
\hline \multicolumn{3}{|c|}{ Challenging features of PBL in perspective of package approach } \\
\hline Waste of time & $\begin{array}{l}\text { It takes lot of time to upload my topic and reply to my group members whole week along, } \\
\text { Continuous along the week and It consume so much time and effort } \\
\text { We can have more TBL in place of PBL as it has only one session }\end{array}$ & $43 / 124$ \\
\hline Larger groups & $\begin{array}{l}\text { Larger group size as compared to TBL hinders our learning } \\
\text { The high number of students in each group, is difficult to manage discussion }\end{array}$ & 23/124 \\
\hline $\begin{array}{l}\text { Lack of structured } \\
\text { feedback }\end{array}$ & $\begin{array}{l}\text { Tutors do not give immediate feedback as in TBL. } \\
\text { I want to have feedback so that I come to know my shortcoming and I want to improve } \\
\text { myself and not loose grades }\end{array}$ & $16 / 124$ \\
\hline \multicolumn{3}{|c|}{ Best features of TBL in perspective of package approach } \\
\hline Teamwork skills & $\begin{array}{l}\text { It teaches me how to deal especially in team working while cooperation and respecting each } \\
\text { other's opinion. } \\
\text { It makes us learn how to respect each other while there are differences in opinion. }\end{array}$ & $40 / 124$ \\
\hline $\begin{array}{l}\text { Group discussion and } \\
\text { competition }\end{array}$ & $\begin{array}{l}\text { Discussions before solving questions allow us to share as much of the previous information } \\
\text { as possible } \\
\text { Competitiveness between the groups motivates us to participate and discuss. } \\
\text { Competition gives us reason to be better }\end{array}$ & $36 / 124$ \\
\hline $\begin{array}{l}\text { Interesting format of } \\
\text { learning }\end{array}$ & $\begin{array}{l}\text { It is interesting way to learn. Never ever forget the information learned in so interesting way, } \\
\text { very engaging } \\
\text { Preparing our PBL objectives for IRAT is useful for our final exams. } \\
\text { While preparing objectives, we actually prepare for block assessments }\end{array}$ & $22 / 124$ \\
\hline \multicolumn{3}{|c|}{ Challenging features of TBL in perspective of package approach } \\
\hline IRAT & $\begin{array}{l}\text { IRAT is difficult sometimes and stressful if there is exam close to week. They should replace } \\
\text { it with GRAT, because IRAT is not team based } \\
\text { IRAT questions of TBL are difficult and not team based. }\end{array}$ & $36 / 124$ \\
\hline $\begin{array}{l}\text { Interdependency in } \\
\text { achieving grades }\end{array}$ & $\begin{array}{l}\text { It totally depends on who is in the group some students just staying without doing anything } \\
\text { Some students relay on others and do not work hard for team } \\
\text { the grade for the session does not represent the effort made by individual student }\end{array}$ & $19 / 124$ \\
\hline
\end{tabular}

The highest perception scores were noted related to item, stating "Different points of view were respected by team members". Many studies have been done around the globe, to identify the effects of team on students' satisfaction and performance. ${ }^{16}$ Results of most of these studies have shown that students were highly satisfied and appreciated the team-based active learning environment. ${ }^{17,18}$ Notably, $75 \%$ of students agreed that in TBL "Team actively elicited multiple points of view before coming to final answer" compared to $67 \%$ in PBL. It is well documented fact that the structure of TBL has elements beneficial to prepare students to work in teams that is essential, particularly within progressively intricate healthcare systems. ${ }^{19}$

Perception scores of female students were higher for both PBL and TBL. Although gender differences in medical education have been reported previously, ${ }^{20}$ there is little evidence in the context of small group learning. Few studies have shown more attention and information sharing in female compared with male tutorial groups. ${ }^{21}$ Results of this study are comparable to the previous research outcome that women tend to support each other by harmonising their interactions; whereas, men more often struggle as individuals to attain and uphold supremacy. ${ }^{22}$ These results are also consistent with the established theories of women's developmental psychology. ${ }^{23}$ In this study, it is interesting to examine that male students are tutored by males; and female students by females. This gender dichotomy is a pre-dominant phenomenon due to separate male and female campuses across the Kingdom.

Thematic content analysis of open-ended data supported this statistical analysis and provided a useful framework of emergent themes to understand students' perspectives in depth. Students were generally inclined towards TBL, due to its interesting collaborative approach, group competition and peer feedback. Students found instant feedback from a content expert helpful for their learning. Several studies have indicated prompt feedback to be more effective than delayed. ${ }^{24}$

During this study, we came up with two noteworthy indica- 
tions: first, students stated a desire for removing I-RAT and making TBL process completely team based and, secondly, they appreciated reflection through G-RAT activity. Although contemplative practices were exercised during PBL sessions, the structured testing procedures in TBL promoted greater level of reflection. The act of reflection is a vital metacognitive skill and there is some evidence that TBL offers several opportunities for informal reflection and improves early cognitive skills. ${ }^{25}$ Moreover, students admitted that the assessment of PBL objectives in IRAT is a good idea to help them prepare for main block assessments. Finally, they appreciated the innovative use of $\mathrm{PBL}$, to enhance personal development through structured presentation skills session. Some of them considered the number of PBL sessions more and suggested replacing with TBL sessions. Overall, the findings of the study support the use of TBL in the modified Package approach.

Admittedly, this study suffers from some limitations. First, it was a single institute study and findings may not be generalised to other institutes. Second, lower than expected response rate due to COVID-19 pandemic, which has affected every aspect of life, making students busy in making personal arrangements towards online education. Third, probably students found the blended approach unique, which may have rendered their responses optimistic. However, given the depth of responses, and the scale of the study, across all academic levels, the authors feel the inferences and commendations are accurate. Although this study established the effectiveness of TBL, more research is recommended to ponder the in-depth association among how and why particular aspects of TBL are effective the way they are.

\section{CONCLUSION}

Students perceived their learning experience in TBL more beneficial as compared to PBL, in blended package approach. They found the novel strategy to be rewarding and enjoyable. The findings of this study suggest a planned and wide scale implementation of hybrid approach, utilising the philosophies of both TBL and PBL to benefit students. Further studies are required to support the blended approach.

\section{ETHICAL APPROVAL:}

Dental Ethics Committee, Qassim University, has approved the research proposal before initiation of the research work.

\section{CONFLICT OF INTEREST:}

The authors declared no conflict of interest.

\section{AUTHORS' CONTRIBUTION:}

SN: Designed study, collected data and contributed to manuscript writing.

MQJ: Collected and analysed data and partially contributed towards article writing.

RB: Contributed to study design and partial manuscript writing.

All the authors read and approved the final manuscript.

\section{REFERENCES}

1. Graffam B. Active learning in medical education: strategies for beginning implementation. Medical Teacher 2007; 29(1):38-42. DOI: 10.1080/01421590601176398.

2. Dolmans D, Michaelsen L, Van Merrienboer J, van der Vleuten C. Should we choose between problem-based learning and team-based learning? No, combine the best of both worlds! Medical teacher 2015; 37:354-359. DOI: 10.3109/0142159X.2014.948828.

3. Yew EH, Goh K. Problem-based learning: An overview of its process and impact on learning. Health Professions Education 2016; 2(2):75-9. http://doi.org/10.1016/ j.hpe.2016.01.004.

4. Barrows HS. Problem based learning in medicine and beyond: A brief overview. New directions for teaching and learning 1996; 1996:3-12. http://doi.org/10.1002/ tl.37219966804.

5. Sayyah M, Shirbandi K, Saki-Malehi A, Rahim F. Use of a problem-based learning teaching model for undergraduate medical and nursing education: a systematic review and meta-analysis. Advances in medical education and practice 2017; 8:691. DOI: 10.2147/AMEP. S143694.

6. Kumar N, Kanchan T, Unnikrishnan B, Thapar R, Mithra $P$, Kulkarni $V$, et al. Incorporating problem based learning into medical curriculum: An experience from a medical college in Mangalore. Indian journal of pharmacology 2017; 49(5):344. DOI: 10.4103/ijp.IJP_492_16.

7. Leupen S. Health Science. Active Learning in College Science: The Case for Evidence-Based Practice 2020; 219.

8. Kenny $\mathrm{P}$, McLaren $\mathrm{H}$, Blissenden M, Villios S. Improving the students' tax experience: A team-based learning approach for undergraduate accounting students. J Australasian Tax Tchrs Ass'n 2015; 10:43.

9. Hamdy $\mathrm{H}$. One size does not fit all: Blended Learning Strategies in Medical Education. Health Professions Education 2015; 1(1):65-6. DOI: 10.1016/j.hpe.2015. 11.007.

10. Bassir SH, Sadr-Eshkevari $\mathrm{P}$, Amirikhorheh $\mathrm{S}$, Karimbux NY. Problem-based learning in dental education: a systematic review of the literature. J Dent Educ 2014; 78:98-109. DOI: 10.1002/j.0022-0337.2014.78.1. tb05661.x

11. Kaliyadan F, Thalamkandathil N, Parupalli SR, Amin T, Balaha $\mathrm{MH}$, Ali WH. English language proficiency and academic performance: A study of a medical preparatory year program in Saudi Arabia. Avicenna J Med 2015; 5:140-4. DOI: 10.4103/2231-0770.165126.

12. Parmelee D, Michaelsen LK, Cook S, Hudes PD. Teambased learning: a practical guide: AMEE guide no. 65. Med Teach 2012; 34(5):e275-87. DOI: 10.3109/ 0142159X.2012.651179.

13. Burgess A, Bleasel J, Haq I, Roberts C, Garsia R, Robertson $T$, et al. Team-based learning (TBL) in the 
medical curriculum: better than PBL?. BMC Med Educ 2017; 17:243. DOI: 10.1186/s12909-017-1068-z.

14. Burgess A, Roberts C, Ayton T, Mellis C. Implementation of modified team-based learning within a problem based learning medical curriculum: a focus group study. BMC Med Educ 2018; 18:74. DOI: 10.1186/ s12909-0181172-8.

15. Hashmi NR. Team Based Learning (TBL) in undergraduate medical education. J Coll Physicians Surg Pak 2014; 24(8):553-6. http://www.jcpsp.pk/ archive/ 2014/ Aug2014/05.pdf.

16. Mansoor M, Aly SM, Javaid A. Effect of Team-based Learning on Second Year Students' Academic Performance. J Coll Physicians Surg Pak 2019; 29(9): 860-4. DOI: 10.29271/jcpsp.2019.09.860.

17. Badar S, Hashmi ZY. Searching the way to keep students awake in class room. Biomedica 2014; 30(1).

18. Jabbar HA, Jarrahi AH, Vamegh MH, Moh'd Alhabahbeh DA, Mahmoud NA, Eladl MA. Effectiveness of the teambased learning (TBL) strategy on medical students' performance. J Taibah Univ Med Sci 2018; 13(1):70. doi: 10.1016/j.jtumed.2017.09.003.

19. Kibble JD, Bellew C, Asmar A, Barkley L. Team-based learning in large enrollment classes. Adv Physiol Educ
2016; 40(4):435-42. doi: 10.1152/advan.00095.2016.

20. Nilsonne A, Fahmy F, Ponzer S. Teaching future physicians about gender differences. Gender of the physician does matter! Lakartidningen 2000; 97: 5329-5332.

21. Das Carlo M, Swadi H, Mpofu D. Medical student perceptions of factors affecting productivity of problem-based learning tutorial groups: does culture influence the outcome?. Teach Learn Med 2003; 15:59-64. DOI: 10.1207/S15328015TLM1501 11.

22. Tannen D. Gender and discourse. Oxford University Press; 1994

23. Fletcher GJ, Simpson JA, Thomas G. Ideals, perceptions, and evaluations in early relationship development. J Pers Soc Psychol 2000; 79:933. DOI: 10.1037//0022-3514. 79.6.933.

24. Li S, Zhu Y, Ellis R. The effects of the timing of corrective feedback on the acquisition of a new linguistic structure. Mod Lang J 2016; 100(1):276-95. http://doi.org/ 10.1111/modl.12315.

25. Tahira QA, Lodhi S, Abaidullah S. Comparison of lecture based and modified team based learning in achieving cognitive skills in medical education. Annals of King Edward Medical University 2018; 24(1):1-7. DOI: 10. 21649/akemu.v24i1.2338. 